\title{
Psychiatric intensive care units, a design for living
}

\author{
Roland Dix and Kelwyn Williams
}

\begin{abstract}
The poychlatric intensive care unit (PICU) is now at the culting edge of acute poychiatic care. Very little guidance has been produced to ensure that the PICU structure and design is able to meet the complex demands put upon it. The creation, development and relocation of a PICU has taken place within the Severn NHS Trust. We describe the experience gained from a recently commissioned unit together with a review of the relevant liferature. Recommendations are offered for core fectures and deston.
\end{abstract}

The demands upon the general adult in-patient facility have become increasingly complex over recent years. With pressure to treat more patients with ever increasing efficiency, patients who demonstrate problematic behaviours have been the subject of considerable attention. The psychiatric intensive care unit (PICU) is now a necessary provision for dealing with patients who demonstrate aggression, suicidal behaviour and a mottvation to abscond (Dix, 1995). The reemergence of the PICU (previously the locked ward) has coincided with the closure of large Victorian institutions in favour of smaller units. In addition, the Reed Committee (1992) have recommended that providers of mental health services include various levels of security in order to improve service provision for mentally disordered offenders.

The Severn NHS Trust has recently commissioned a PICU. The service was first established in a specially converted ward in a Victorian institution. It was relocated to a brand new building on the site of a District General Hospital. The physical environment in which the acutely disturbed patient is treated has had a major impact on the quality and efficacy of clinical intervention that can be provided, however no standard exists for the structure and design of the PICU.

\section{Review of the literature}

Little has been published in terms of recommendations for PICU design. The first real guidelines related to secure units and appeared in the DHSS document Regional Secure Units: Design Guide, in 1975. The recommendations produced advised on the level of prison-type security, the discreteness of this and the need for the secure unit to blend in with the surrounding hospital. In a survey of the regional secure unit programme carried out in 1985, Snowden criticised cramped conditions, poor ventilation and limited clinical interview rooms in some RSUs.

These guidelines were superseded with the publication in 1993 by NHS Estates of the Design Guide-Medium Secure Psychiatric Units which took on board criticisms made by Snowden and included recommendations from a multidisciplinary team evaluation. Important points were made regarding standards of space, patient numbers (ideally six), window and door security, seclusion rooms, daytime facilities and observation.

However, it was in the early 1980 s in the USA that PICUs began to be developed as an adjunct to psychiatric units to cope with problematic behaviour resulting from the acute phase of mental illness. Allan et al (1988) described the planning of a psychiatric intensive care unit. They placed little emphasis in their paper on actual design considerations, except in noting the need for ample space and the facility to observe patients continuously. Musisi et al (1989) described the operation of a psychiatric intenstve care unit in a provincial hospital in Toronto. Their unit centred on a large, easily observed open area with six dormitory style beds separated by rectangle privacy drapes. Positioning of the nursing station allowed observation of all patients. There were separate lounge and dining areas, a bathroom, meeting room and emergency buzzer system. The importance of the need for continuous observation was stressed with one-way mirrors and plexiglass in the nursing station. A survey of nurses' attitudes proposed a strengthening of windows for the observation station and improved sound-proofing of the quiet rooms.

Some studies have addressed area, patient density and over-crowding on intensive care units. Khan et al (1987), of the Harbourview Medical Center in Seattle, describe a ward offering each patient (five in all) 284 square feet of dayroom space and speculated on the antipsychotic effect of the milieu (1987, 1990). 
Palmstierna et al (1991) reported on the relationship between increased number of patients on the ward and increased likelihood of aggresstve behaviour, again highlighting the need for adequate space.

The concept of the specialised PICU, usurping the old style 'locked ward' crossed the Atlantic in the early 1990s with the Reed Report (Reed Committee, 1992), establishing the PICU as part of UK adult mental health provision. These new units tended to be adapted from the pre-existing facilities on acute psychiatric units, but few, if any, guidelines for design existed. Reporting of British PICU experience with reference to design features has been scanty. In looking at the principles and problems of psychiatric intensive care, Hyde \& Harrower-Wilson (1994), endorsed the need for a locked ward, special observation and quiet rooms. Zigmond (1995) talked of the need to maintain the fabric and furniture of the ward so as to keep an acceptable environment. Recent attention has focused on personal security. Lillywhite (1995), looking at the risk of violence to junior psychiatrists, made recommendations for the design of interview rooms, namely that they should be close to staff areas; have an alarm system; have a door opening outwards; have a means for unobtrustve observation; and be quiet and private.

\section{Recommendations for PICU design}

The Severn NHS Trust PICU became operational in July 1994. The cost of converting the rehabilitation ward for use as a PICU was in the region of $\$ 20000$. Five weeks were needed for the work to be completed. The appointed nurse manager for the unit had complete control over the modifications to the ward. After seven months in the converted ward the service was relocated to a brand new building. The new ward was approximately one-third of the size of its predecessor. Before the move to the new unit, and after the relocation, further modifications to the new ward proved necessary.

Converting a ward in the Victorian institution for use as a PICU and its subsequent relocation to the brand new building has proved insightful. With a review of the relevant literature, we are able to make a number of suggestions that may be useful in designing an effecttve PICU environment. The following points are intended to show the design considerations that differ from a standard acute ward and a medium secure unit.

\section{Ward positioning and layout}

The PICU should be sited on the ground floor with access to an enclosed garden. An entrance to the ward, which does not require travelling through the rest of the building, should be avallable for acutely disturbed admissions. This should preferably be near the extra care area (see below). Four abreast should be comfortably accommodated by all corridors. Each patient should have their own bedroom. Six to eight beds is a good number.

\section{Security}

The main entrance to the PICU should be sited away from the main clinical area of the ward. This will help prevent absconding at times when the entrance is in use. A lockable door is desirable, but the electronic key pad should be avoided as patients soon become familiar with the combination. Windows should have a limited opening and be of durable design. Within the garden area standard garden fencing or hedges should be sufficient as it is intended to provide a recreational area with obstacles to absconding rather than the more elaborate security of a medium secure unit. Fire exits can be secured on magnetic locks that open if the fire alarm is activated.

\section{Special clinical facillities}

Seclusion rooms have lost favour in recent times. The PICU should include a facility away from the main clinical area in which a single acutely disturbed patient can be nursed, commonly referred to as an extra care area (ECA). Unless staff numbers will allow two nurses to be dedicated to the ECA it should not be separated from the rest of the ward by means of a physical barrier (i.e. wall or partition). The ECA should be able to provide for the daily living needs of a single patient and include the following, all in close proximity to each other: a room in which up to five people being a three person control and restraint team, the patient and one other could fit into comfortably, and the physical composition of which meets the Mental Health Act Commission standards for a seclusion room; a showering and washing facility with a toilet; a quiet room with simple furnishings.

\section{Recreation}

A general activities room in which items such as a pool table and table tennis can be comfortably accommodated should be provided, as well as a good size quiet room with a television and music centre away from the main day room.

\section{Observation and safety}

Numerous corners and corridors should be avoided. Where corridors meet convex mirrors 
can be fitted at ceiling level to promote nonobtrusive observation. Disturbance buttons (with audiovisual output) should be placed in all rooms. This system should have the provision to be deactivated centrally in the event of persistent, inappropriate use by patients. In-built transmitter receiver type ultrasonic personal alarm systems are useful for indicating an emergency. All doors should open both ways. Bedroom doors should be fitted with a louvre type observation panel, operated from the outside. All other doors should be fitted with a plexiglass window (with the exception of bathroom and toilet). Each bedroom should have a vandal-proof light fitting, which can be dimmed and operated from the outside of the room for night time observation. Some bedrooms should be without electrical sockets in the event that additional safety is required.

\section{Firtures and fittings}

The ward environment should be as homely as possible. Wall mounted pictures, pot plants and non-moulded furniture may be used with discretion as items of this type promote a relaxed environment and do not present a significant risk to safety. Plastic mirrors should be used in all the appropriate areas. A public telephone should be fitted within the ward.

\section{Comment}

The role of the PICU in the provision of acute mental health care is becoming increasingly important. Its place in the in-patient spectrum is fixed between the acute ward and the RSU, although the RSU may be the closer cousin. The recent policy of making PICU beds available to mentally disordered offenders with its implication for security has emphasised the need for PICUs to be designed carefully. Mixing patients who have offended and have a legal requirement to remain in a PICU with patients who are acutely disturbed is a complex equation. We would hypothesise that much dissatisfaction exists among clinicians with the design of PICUs in many new hospital developments. It is often wrongly assumed that the length of stay of patients in the PICU will be very short and consequently that comprehensive internal facilities are unnecessary. However, the opposite may be the case (Citrome et al, 1994). The clinical focus of the PICU often requires that on a day to day basis, the patient spends more time on the ward and escort is often necessary when patients do leave the ward. In view of this, it can be argued that the PICU should contain a more comprehenstve range of internal facilities than that of general acute wards.

The PICU is the reality of modern mental health care for the acutely disturbed patient. Crucial to that care is the environment in which it is provided. To date the design aspects of these units has been neglected. We have outlined what we consider to be core features of structure and design. We recommend that a comprehenstve document, similar to that available for the design of medium secure units, is urgently needed.

\section{References}

AlLAN, E., BROWN, R. \& LAURY, G. (1988) Planning a psychiatric intenstve care unit. Hospital and Community Psychiatry, 39, 81-83.

CITROME, L., GREEN, L. \& RICHARD, F. (1994) Length of stay and recidivism on a psychiatric intenstve care unit. Hospital and Community Psychiatry, 46, 74-77.

DHSS (1975) Regional Secure Units: Design Guidelines. London: HMSO.

Dix, R. (1995) A nurse led psychiatric intenstve care unit. Psychiatric Bulletin, 19, 285-287.

HYDE, C. \& HARROWER-WILSON, C. (1994) Psychiatric intenstve care-principles and problems. Hospital Update, May, 287-295.

Khan, A., CoHEN, S., CHIIES, J., et al (1987) Therapeutic role of a psychiatric intensive care unit in acute psychosis. Comprehenstue Psychiatry, 28, 264-269.

LILYWHITE, A., MORGAN, N. \& WALTER, E. (1995) Reducing the risk of violence to junior psychiatrists. Psychiatric Bulletin, 19, 24-27.

Musisi, S. M., WAYLENK, D. A. \& RAPp, M. S. (1989) A psychiatric intenstve care unit in a psychiatric hospital. Canadian Journal of Psychiatry. 34, 200-204.

NATONAL HEALTH SERVICE (1993) Design Guide - Medium Secure Psychiatric Units. London: NHS Estates Department.

Palmstierna, J., Humfelt, B. \& WistedT, B. (1991) The relationship of crowding and aggresstve behaviour on a psychiatric intensive care unit. Hospital and Community Psychiatry, 42, 1237-1240.

REED COMMITIEE (1992) Review of Health and Social Services for Mentally Disordered Offenders and Others Requiring Similar Services. London: Department of Health/Home Offlice.

SNOWDEN. P. (1985) A survey of the regional secure unit programme. British Joumal of Psychiatry, 147, 499-507.

ZigmOND, A. (1995) Special care wards - are they special? Psychiatric Bulletin, 19, 24-27.

*Roland Dix, Clinical Nurse Specialist, Psychiatric Intensive Care Unit, Wotton Lawn Hospital, Horton Road, Gloucester GL1 3PX; and Kelwyn Williams, Registrar in Psychiatry. Wotton Lawn Hospital, Horton Road, Gloucester GL1 3PX

*Correspondence 